NASA Technical Memorandum 107403

\title{
Atomic Oxygen Treatment Technique for Removal of Smoke Damage From Paintings
}

S.K. Rutledge and B.A. Banks

Lewis Research Center

Cleveland, Ohio

Prepared for the

Fall Meeting

sponsored by the Materials Research Society

Boston, Massachusetts, December 2-6, 1996

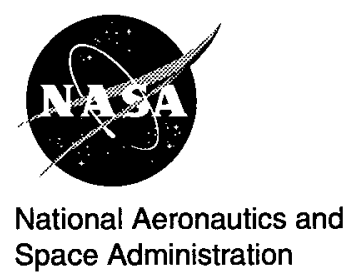





\title{
ATOMIC OXYGEN TREATMENT TECHNIQUE FOR REMOVAL OF SMOKE DAMAGE FROM PAINTINGS
}

\author{
S.K. RUTLEDGE, B.A. BANKS \\ NASA Lewis Research Center \\ Cleveland, OH 44135 \\ Sharon.K.Rutledge@LeRC.NASA.GOV
}

\begin{abstract}
Soot deposits that can accumulate on surfaces of a painting during a fire can be difficult to clean from some types of paintings without damaging the underlying paint layers. A non-contact technique has been developed which can remove the soot by allowing a gas containing atomic oxygen to flow over the surface and chemically react with the soot to form carbon monoxide and carbon dioxide. The reaction is limited to the surface, so the underlying paint is not touched. The process can be controlled so that the cleaning can be stopped once the paint surface is reached. This paper describes the smoke exposure and cleaning of untreated canvas, acrylic gesso, and sections of an oil painting using this technique. The samples were characterized by optical microscopy and reflectance spectroscopy.
\end{abstract}

\section{INTRODUCTION}

Fires in museums and public buildings can result in complete destruction of artwork on display or can soil the artwork with accumulated soot to an extent to which it can no longer be used for study or be enjoyed by the public. In situations where the surface has not undergone extensive charring or melting, restoration attempts can be made. However, soot deposits can be very difficult to remove from some types of painted surfaces, particularly those prepared with an acrylic medium or those where the paint is fragile or flaking. Restoration typically involves the use of organic solvents to clean the surface [1]. But these solvents may cause swelling or leaching of the paint layers [2]. Immersion of the surface, or swabbing during solvent cleaning may also cause pigment movement or removal through mechanical contact.

A non-contact technique of removing organic deposits from surfaces was developed out of NASA research on the effect of oxygen atoms on various materials. Atomic oxygen is of interest because it is present in the atmosphere surrounding Earth at altitudes where satellites typically orbit. It has been shown to react chemically with coatings or deposits that contain carbon which are present on the surface of a material [3-4]. In the reaction, the carbon is converted to mostly carbon monoxide and some carbon dioxide. Water vapor is also a byproduct of the reaction if the surface contains carbon-hydrogen bonds. As a result of the need to study this reaction that takes place in Earth's upper atmosphere, facilities have been developed which can produce atomic oxygen on Earth for material exposure and testing [5]. Radio frequency, microwave, or electron bombardment can be used to split molecular oxygen into atomic oxygen. These atoms at low energy can be directed to a surface, like a gentle shower, or allowed to surround the object, as in a bath. The exposure is performed in a vacuum chamber where pressures can range from 100 to 0.001 millitorr depending on the technique used. Because it is a dry process, there is no risk of leaching or swelling. In addition, the atomic oxygen reaction is confined to the surface which minimizes the risk to the paint or underlying canvas. Because the technique seems to provide an attractive alternative to present cleaning techniques, a series of tests were performed in order to determine the effectiveness of atomic oxygen in removing soot, produced in some simulated fires, from some typical painting surfaces.

\section{PROCEDURE}

\section{Samples Used for Testing}

Samples used for smoke exposure and cleaning consisted of cotton canvas and canvas prepared with acrylic gesso purchased from the Cleveland Institute of Art supply shop, and sections from a greater than fifteen year old donated portrait of a woman made with oil paint on gesso. The two 2"x2" sections used in the test were carefully cut 
from the forehead and shoulder areas of the painting with a scalpel in order to capture areas with the greatest color changes, brushstroke details and impasto. General color changes were looked for, however, the sample was limited in color variety and the pigments were not documented. Most of the testing focused on the effects of the cleaning process on gesso and canvas where changes in spectral response, and appearance could be made.

\section{$\underline{\text { Smoke Exposure }}$}

Two different smoke exposures were used to simulate building fires. The first test was performed at the Cleveland Fire Department Training Facility, which offered an opportunity to simulate the type of smoke that would be present in a house fire. The training facility consists of a two story building with corrugated metal outer walls and firewall separating rooms inside. The interior firewall is outfitted with thermocouples at spaced intervals from floor to ceiling so that the wall temperature can be monitored during a fire. In this test, samples of gesso and canvas were attached to the interior firewall of one room using small nails. Near the opposite wall of the small room, three upholstered chairs, a wood lamp table and lamp and a wood end table were placed. A lit match thrown into a metal bucket waste container holding newspaper was used to start the fire. A thin layer of straw spread on the concrete floor and a newspaper wick from the bucket to the straw helped to spread the fire to the furniture. During the fire, the wall temperature where the samples were hung did not exceed $177^{\circ} \mathrm{C}$. The fire was allowed to burn for about 23 minutes before being extinguished by the fire department with a water hose. Care was taken not to get the samples wet while putting out the fire. All that remained of the furniture were the metal frames and springs and a few pieces of wood from furniture legs. After the room cooled down, samples were carefully removed from the wall. It was noted that samples placed near the ceiling of the room received a thicker covering of soot, while those near the floor had only a very thin veil of soot. Samples were photodocumented before and after the fire. The soot on the surfaces, even near the ceiling level, still was not very thick.

In a desire to obtain a thicker smoke layer on the surfaces, a smaller metal chamber was fashioned out of an electrical circuit breaker box. A hole with a sliding door was made at the top of one end of the box to serve as a vent stack and at the bottom in the opposite end was placed a small metal can containing a rolled rag soaked in 10W-40 motor oil, which was the fire source. The samples were hung on the side wall near the vent using binder clips attached to metal hooks. The samples exposed were gesso and the oil painting sections. The sections of the painting were attached to gesso strips with copper wire for hanging. A thermocouple suspended into the vent stack provided an indication of the temperature inside the box. The extent of the smoke deposit was measured using the current reading from a small illuminated solar cell that was protected with a glass slide. As soot built up on the slide, less of the light from two nearby lamps could reach the solar cell. This would make the monitored current reading drop. Taking into account the soot buildup on the lamps, the test was stopped when there was estimated to be an $80 \%$ reduction in transmittance of light through the slide on top of the cell. This took approximately one hour. The temperature during this fire did not exceed $84^{\circ} \mathrm{C}$. After exposure the smoke source was removed from the box and extinguished. Samples were photodocumented prior to and after smoke exposure.

\section{Atomic Oxygen Cleaning}

Cleaning of the samples after smoke exposure was performed in a commercial radio frequency plasma chamber (SPI Plasma Prep II) operated using air to produce atomic oxygen. The chamber size was approximately $10.5 \mathrm{~cm}$ in diameter by $15 \mathrm{~cm}$ long. The pressure in the chamber during exposure was approximately 100 millitorr. The back sides of the canvas, gesso and painting samples were protected from the cleaning process by use of a glass backing plate. Samples were laid on the plate but not physically attached.

\section{Analysis}

A Perkin-Elmer Lambda-9 spectrophotometer was used to observe the change in reflectance from the canvas and gesso surfaces caused by soot deposition and subsequent cleaning. Reflectance as a function of wavelength from 400 to $700 \mathrm{~nm}$ (visible range) was measured as a means of accurately monitoring color changes on these samples. The painting sections were not analyzed because there was not enough area of any particular color on these samples to obtain an accurate measurement. Samples were also visually examined with an Olympus SZH optical microscope. Exposed samples were compared to unexposed control samples. 


\section{RESULTS AND DISCUSSION}

Although the samples exposed in the fire at the Cleveland Fire Department Training Facility did not darken as much as expected, there was still a change in coloration of the exposed canvas and gesso from white to tan. This color change was easily detected with the spectrophotometer as can be seen in Figure 1. The gesso and canvas were sectioned so that various degrees of cleaning could be tried on each sample to determine the effect of different doses of atomic oxygen on the soot and underlying material. As can be seen in Figure 1, the canvas surface reflectance
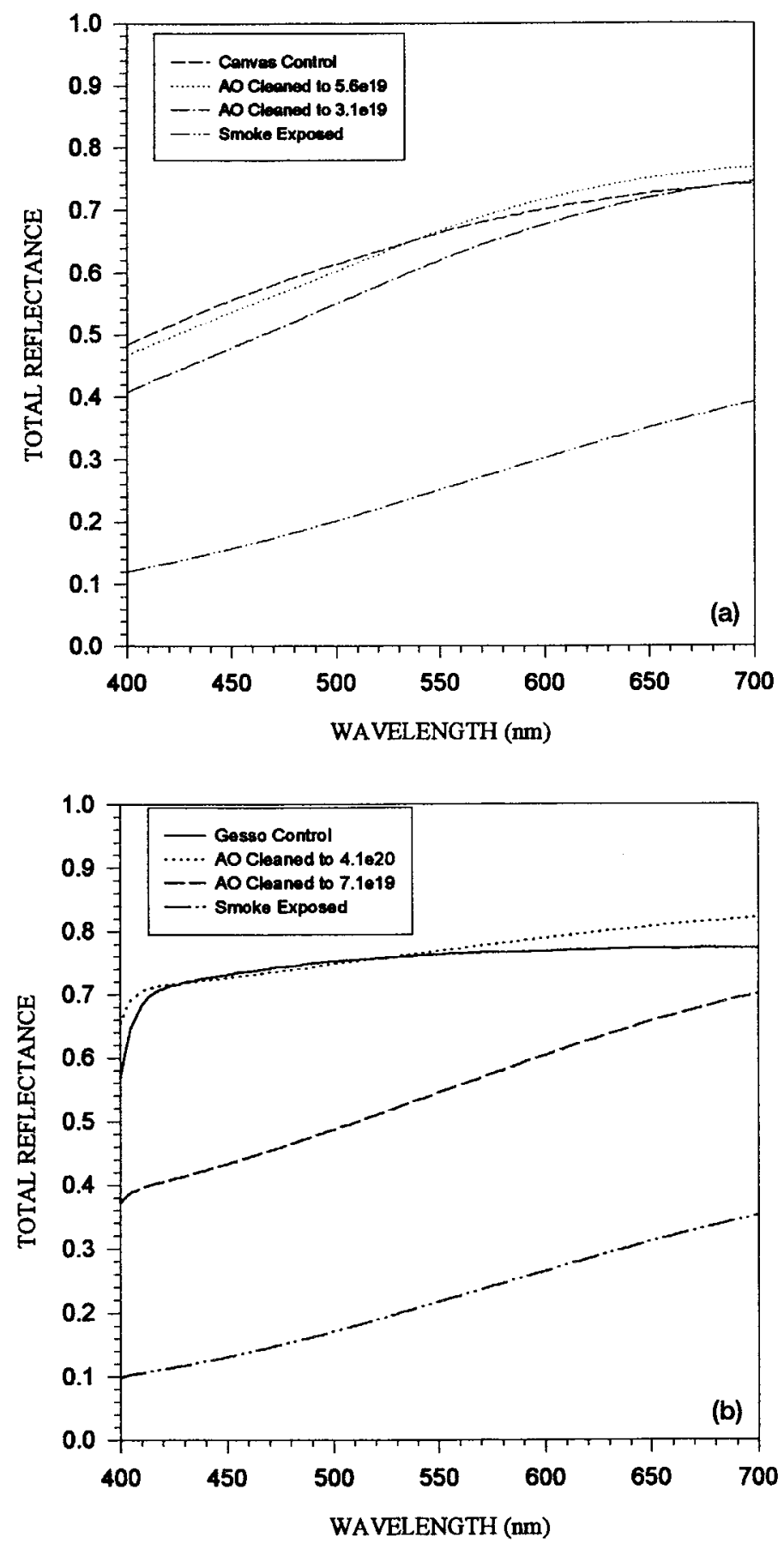

Figure 1.-Effect of atomic oxygen cleaning dose in atoms $/ \mathrm{cm}^{2}$ on smoke exposed canvas (a) and gesso (b). 
recovered rapidly with atomic oxygen cleaning to levels near that of the original surface. The recorded dose of atoms of atomic oxygen accumulated over a square centimeter of the surface area needed for recovery took a little over three hours to achieve. The gesso material also recovered with atomic oxygen exposure, but took longer to reach nearly the same coloration as the original, approximately 23 hours. The same amount of soot was deposited onto the canvas as the gesso, but the canvas has a much greater surface area due to the weave of the fabric. This may result in a thinner deposit overall. As can be seen in Figures $1 \mathrm{a}$ and $1 \mathrm{~b}$, the atomic oxygen cleaned sample reflectance scans closely approximate but never reach an exact match with the original. When the surface appears to be fully clean, the reflectance of the surface is slightly higher than that of the original at longer wavelengths. The reason for this can be observed in the microscope photographs in Figure 2. The surfaces originally have a gloss to them (Figures $2 a$ and $d$ ). The smoke particles shown clinging to the surfaces in Figures $2 b$ and e are removed by the atomic oxygen, but since the fabric sizing and the acrylic gesso are also organic, a small amount of these materials are removed. This results in a less glossy, more diffusely reflecting surface as shown in Figures $2 \mathrm{c}$ and $\mathrm{f}$. Because the reflectance measurement is that of the total reflectance from the surface, the increased surface area due to the slight surface texturing scatters more light and increases the total reflectance response. A similar dulling of the surface is observed following conventional cleaning techniques.

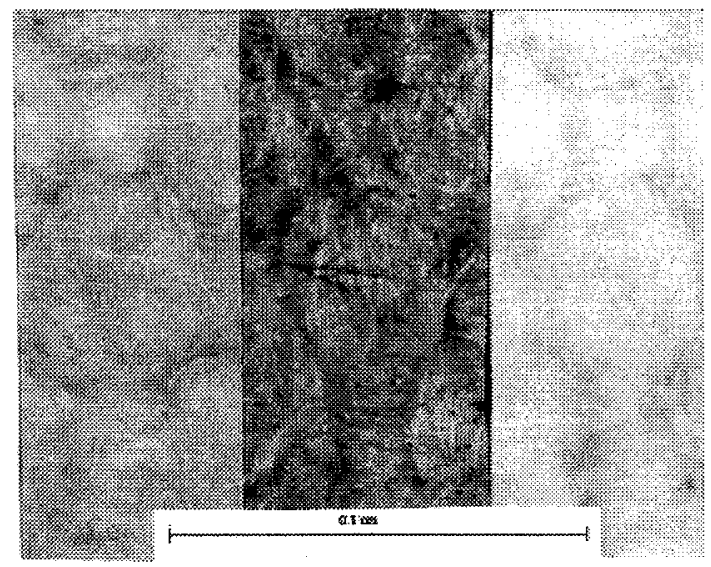

(a) (b) (c)

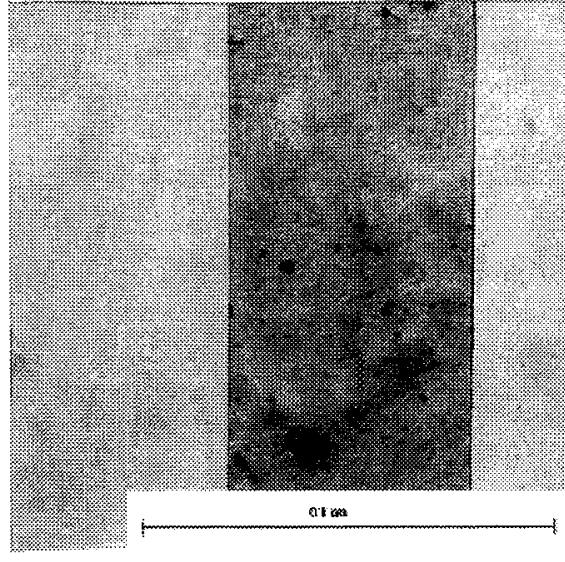

(d) (e)

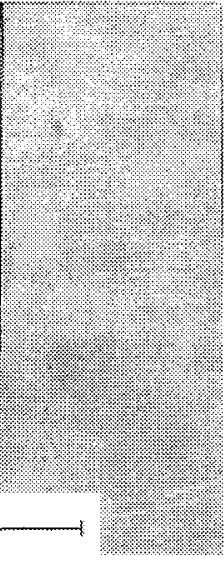

(f)

Figure 2.-Optical microphoto comparison of canvas (a-c) and gesso (d-f) under the following test conditions: (a) Unexposed canvas; (b) Smoke exposed canvas; (c) Canvas, smoke exposed then cleaned with atomic oxygen to $5.6 \times 10^{19}$ atoms $/ \mathrm{cm}^{2}$; (d) Unexposed gesso; (e) Smoke exposed gesso; (f) Gesso smoke exposed then cleaned with atomic oxygen to $7.1 \times 10^{19}$ atoms $/ \mathrm{cm}^{2}$. (Scale marker on photos represents $0.1 \mathrm{~cm}$ )

Both microscope photo series in Figure 2 illustrate the ability of atomic oxygen to remove smoke particles from the surface without altering the overall surface structure. No cracking due to dehydration from being cleaned in a vacuum chamber was observed on any of the samples. The material never reaches full dehydration, because the cleaning time is much shorter than the time for the residual moisture to be drawn out of the painting (at least $48 \mathrm{hrs}$ ). Overcleaning can result in a detrimental loss of sizing in the canvas or increased porosity in the gesso. This can be avoided by monitoring of the surface during exposure through visual techniques such as observation through a window or camera, or reflectance scan monitoring. The cleaning process is uniform, and can be stopped at any point in the soot removal process.

Similar results were observed for the gesso exposed during the oil fire, however, the soot was removed in much less time, slightly less than an hour. Even though the soot was believed to be thicker on this surface, it was a more pure carbon deposit and was fairly black. This made it an easier material to oxidize. It may have been more difficult to remove soot from the furniture fire because the soot is believed to contain a blend of many different, less oxidizable, organics and inorganics. The oil painting sections were cleaned to levels near that of the gesso. A photo series taken from the forehead area is contained in Figure 3. With careful cleaning, the soot that totally obscured the detail in this section of the forehead shown in Figure $3 \mathrm{~b}$ could be removed. 
Figure $3 \mathrm{c}$ shows the final result after cleaning. The sections were placed back into the original painting so that changes in gloss, detail or coloration could be observed. After cleaning to an atomic oxygen exposure dose of $3 \times 10^{19}$ atoms $/ \mathrm{cm}^{2}$, the sections were restored to their original coloration and gloss. There was no apparent loss of any impasto regions or brushstrokes. Further exposure tests are planned using a series of well documented acrylic pigments on gesso in order to verify color and gloss durability on these more sensitive materials.

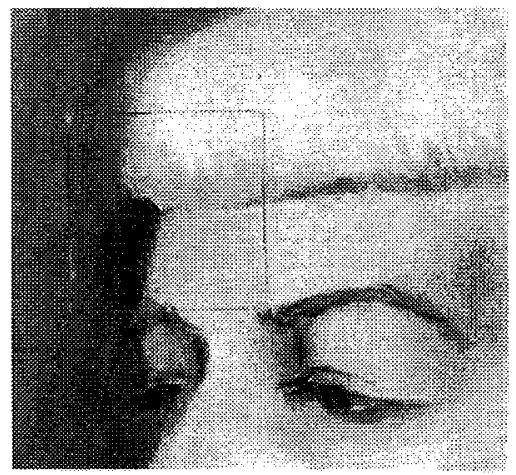

(a)

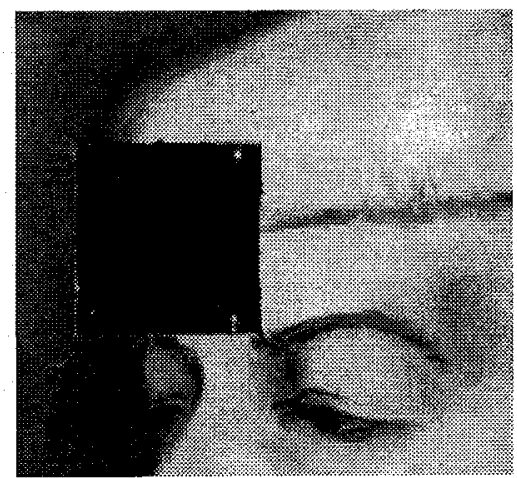

(b)

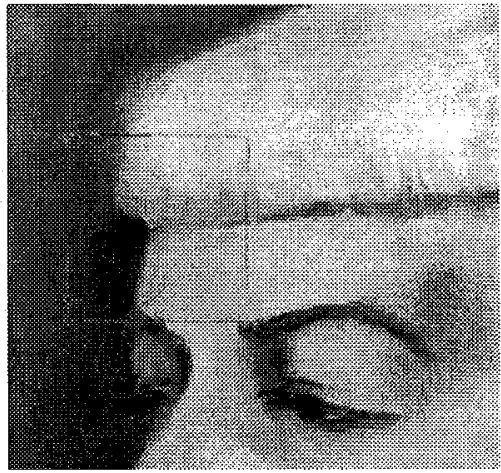

(c)

Figure 3.-Oil painting: (a) unexposed, showing location of removed section; (b) with smoke exposed section set back in; (c) after cleaning smoke exposed section with atomic oxygen.

\section{CONCLUSIONS}

Although further tests are needed to verify the safety of the atomic oxygen cleaning process for use on paintings, preliminary results appear to be promising. The process appears to work well for removing soot from both canvas and gesso, allowing them to be restored to their original coloration without changing the overall surface roughness. There is a slight increase in diffuse reflectance as a result of cleaning, however, it is similar to that which is observed with solvent cleaning and the process can be stopped sooner by either visual observation or surface reflectance monitoring. The oil painting that was cleaned was restored without changes in coloration, surface texture, or gloss. This process may provide a viable alternative to other cleaning techniques and add an additional tool for use by conservators. It is especially attractive for cases in which soot cannot be removed from a surface acceptably or safely by conventional techniques.

\section{ACKNOWLEDGEMENTS}

The authors would like to give a special thanks to Captain Smith and Lt. Peterson of the Cleveland Fire Department for all of their help with setting up and running the simulated house fire at their Training Facility. Also thank you to Priscilla Diem and Monica Crabtree-Reusser at the Great Lakes Regional Technology Transfer Center (GLITeC) for locating a sacrificial painting for use in the testing. The painting was made by Monica's mother Marilyn Engel.

\section{REFERENCES}

E.R. de la Rie, Analytical Chemistry, 61, 21 (Nov. 1, 1989).

R.L. Feller, N. Stolow, E.H. Jones, On Picture Varnishes and Their Solvents, National Gallery of Art: Washington D.C., 1985, pp 47-116.

B. Banks, et al. NASA/SDIO Space Environmental Effects on Materials Workshop, 1988, NASA Conference Publication 3035, pp 197-239.

B. Banks, S. Rutledge, Proceedings of the Fourth European Symposium on Spacecraft Materials in Space Environment, CERT, Toulouse, France, Sept. 6-9, 1988, pp 371-392.

B. Banks, et al. Proceedings of the $18^{\text {th }}$ Annual Symposium on Applied Vacuum Science and Technology, 1989, NASA TM-101971. 
Public reporting burden for this collection of information is estimated to average 1 hour per response, including the time for reviewing instructions, searching existing data sources, gathering and maintaining the data needed, and completing and reviewing the collection of information. Send comments regarding this burden estimate or any other aspect of this this burden, to Washington Headquarters Services, Directorate for Information Operations and Reports, 1215 Jefferson Davis Highway, Suite 1204, Arlington, VA 22202-4302, and to the Office of Management and Budget, Paperwork Reduction Project (0704-0188), Washington, DC 20503.

\begin{tabular}{|l|c|c|}
\hline 1. AGENCY USE ONLY (Leave blank) & $\begin{array}{c}\text { 2. REPORT DATE } \\
\text { January } 1997\end{array}$ & $\begin{array}{c}\text { 3. REPORT TYPE AND DATES COVERED } \\
\text { Technical Memorandum }\end{array}$ \\
\hline
\end{tabular}

4. TITLE AND SUBTITLE

Atomic Oxygen Treatment Technique for Removal of Smoke Damage From Paintings

6. AUTHOR(S)
5. FUNDING NUMBERS

WU-632-1A-1E

S.K. Rutledge and B.A. Banks

\section{PERFORMING ORGANIZATION NAME(S) AND ADDRESS(ES)}

National Aeronautics and Space Administration

Lewis Research Center

Cleveland, Ohio 44135-3191
8. PERFORMING ORGANIZATION REPORT NUMBER

E-10610

\section{SPONSORING/MONITORING AGENCY NAME(S) AND ADDRESS(ES)}

National Aeronautics and Space Administration

Washington, DC 20546-0001
10. SPONSORING/MONITORING AGENCY REPORT NUMBER

NASA TM-107403

\section{SUPPLEMENTARY NOTES}

Prepared for the Fall Meeting sponsored by the Materials Research Society, Boston, Massachusetts, December 2-6, 1996. Responsible person, S.K. Rutledge, organization code 5480, (216) 433-2219.

12a. DISTRIBUTION/AVAILABILITY STATEMENT

12b. DISTRIBUTION CODE

Unclassified -Unlimited

Subject Category 27

This publication is available from the NASA Center for AeroSpace Information, (301) 621-0390.

13. ABSTRACT (Maximum 200 words)

Soot deposits that can accumulate on surfaces of a painting during a fire can be difficult to clean from some types of paintings without damaging the underlying paint layers. A non-contact technique has been developed which can remove the soot by allowing a gas containing atomic oxygen to flow over the surface and chemically react with the soot to form carbon monoxide and carbon dioxide. The reaction is limited to the surface, so the underlying paint is not touched. The process can be controlled so that the cleaning can be stopped once the paint surface is reached. This paper describes the smoke exposure and cleaning of untreated canvas, acrylic gesso, and sections of an oil painting using this technique. The samples were characterized by optical microscopy and reflectance spectroscopy.

\begin{tabular}{|c|c|c|}
\hline 14. SUBJECT TERMS \\
Atomic OXygen; Art restoration; Conservation; Soot; Fire damage \\
\hline $\begin{array}{c}\text { 17. SECURITY CLASSIFICATION } \\
\text { OF REPORT } \\
\text { Unclassified }\end{array}$ & $\begin{array}{c}\text { 18. SECURITY CLASSIFICATION } \\
\text { OF THIS PAGE } \\
\text { Unclassified }\end{array}$ & $\begin{array}{c}\text { 19. SECURITY CLASSIFICATION } \\
\text { OF ABSTRACT } \\
\text { Unclassified }\end{array}$ \\
\hline
\end{tabular}

\section{NUMBER OF PAGES}

16. PRICE CODE

$\mathrm{A} 02$

20. LIMITATION OF ABSTRACT 
National Aeronautics and

Space Administration

Lewis Research Center

21000 Brookpark Rd.

Cleveland, $\mathrm{OH}$ 44135-3191

Official Business

Penally for Private Use $\$ 300$

POSTMASTER: If Undeliverable - Do Not Return 